\title{
La investigación-creación, generador de conocimiento para la construcción de un museo virtual del patrimonio científico y cultural del Dr. Jorge Reynolds Pombo ${ }^{1}$
}

\section{Artículo de investigación}

\section{William Ruiz Joya}

Docente investigador Fundación Universitaria del Área Andina

wruiz@areandina.edu.co

\section{Héctor Córdoba Salamanca}

Docente investigador Fundación Universitaria del Área Andina

hcordoba@areandina.edu.co

\section{Olga Lucía Zipa Patiño}

Docente Fundación Universitaria del Área Andina ozipa@areandina.edu.co

\section{(c) (i)}

https://creativecommons.org/licenses/by/4.0/deed.es
Recibido: 26 de junio de 2017

Aprobado: 18 de diciembre de 2017

Cómo citar este artículo: Ruiz Joya, William; Córdoba Salamanca, Héctor; Zipa Patiño, Olga Lucía (2019). La investigación-creación, generador de conocimiento para la construcción de un museo virtual del patrimonio científico y cultural del Dr. Jorge Reynolds Pombo. Calle 14: revista de investigación en el campo del arte 14(25), pp. 206-223. DOI: https://doi. org/10.14483/21450706.14077

Dr. Jorge Reynold. Foto: Pan Amerinan Helt Organization PAHO. https://www.flickr.com/photos/pahowho/9401100883/in/album72157634865293590/ 


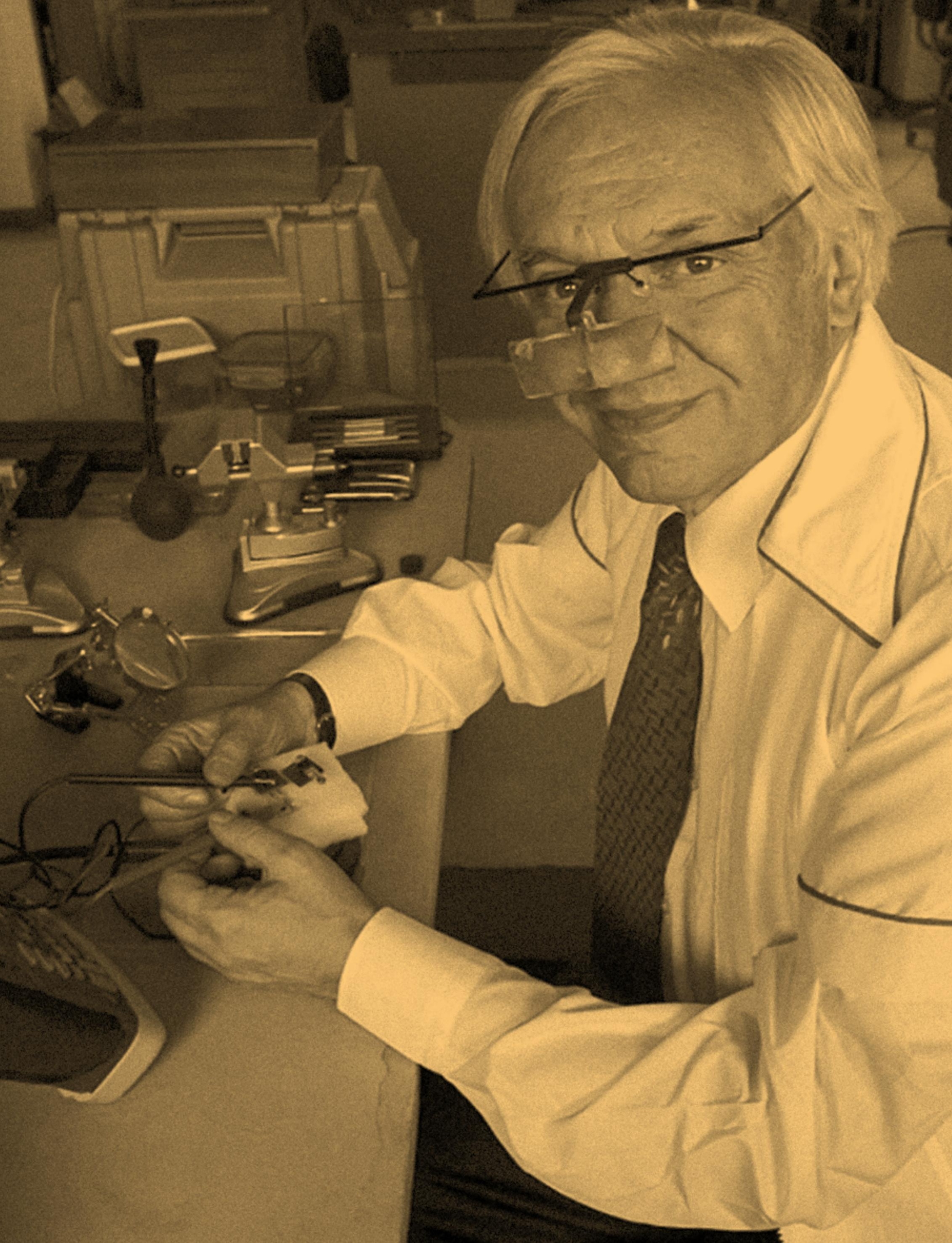


La investigación-creación, generadora de conocimiento para la construcción de un museo virtual del patrimonio científico y cultural del Dr. Jorge Reynolds Pombo

\title{
Resumen
}

El macroproyecto del Museo Virtual Dr. Jorge Reynolds Pombo, se plantea a partir de cuatro etapas: la primera se refiere a conocer cuáles son las estrategias para el análisis de las fuentes de información de las obras, los saberes y objetos de las investigaciones desarrolladas por el Dr. Jorge Reynolds Pombo, para la divulgación en un Museo Virtual; aquí, diseñar las estrategias se convierte en la primera fase del proyecto; con base en lo anterior, se establece el marco referencial en la identificación de lo virtual, de la catalogación, el museo y el patrimonio cultural y científico. Estos aspectos llevaron a generar instrumentos de recolección de datos a partir de aplicaciones tecnológicas y, con dichos datos, se organizó y planteó la información documental para determinar las colecciones que serán estructura del Museo Virtual, mostrando lo necesaria de la continuidad en la consecución de los objetivos en las otras fases del museo.

\section{Palabras claves}

Comunicación Web; exposiciones interactivas; multimedia; museos virtuales; patrimonio; Reynolds Pombo

Research-creation, generator of knowledge for the construction of a virtual museum of the scientific and cultural heritage of Dr. Jorge Reynolds Pombo

\begin{abstract}
The macroproject of the Dr. Jorge Reynolds Pombo Virtual Museum is composed of four stages; the first refers to discovering the strategies for the analysis of the information sources of the works, interests and objects of research developed by Dr. Jorge Reynolds Pombo, for their dissemination in a Virtual Museum. Based on this, a referential framework is established in the identification of virtual, catalogue, museum, and cultural and scientific heritage elements. These aspects led to the generation of data collection tools based on technological applications and, with these data, the organizing and presentation of the documentary information to determine the collections of the Virtual Museum was carried out. Continuity was shown to be a key element in achieving the objectives of the other phases of the museum.
\end{abstract}

\section{Keywords}

Web publishing; interactive exhibitions; multimedia; virtual museums; heritage; Reynolds Pombo

La recherche-création, génératrice de connaissances pour la construction d'un musée virtuel du patrimoine scientifique et culturel du Dr. Jorge Reynolds Pombo

\section{Résumé}

Le macroprojet du musée virtuel Dr. Jorge Reynolds Pombo est composé de quatre étapes ; la première concerne la connaissance des stratégies d'analyse des sources d'information sur les œuvres, les journaux et les objets de recherche développés par le Dr Jorge Reynolds Pombo en vue de leur diffusion dans un musée virtuel. Sur cette base, un cadre de référence est établi pour l'identification d'éléments virtuels, de catalogues, de musées, et de patrimoine culturel et scientifique; aspects qui ont conduit à la génération d'outils de collecte de données basés sur des applications technologiques et, avec ces données, à l'organisation et à la présentation des informations documentaires afin de déterminer les collections qui constitueront la structure du musée virtuel. De la continuité est nécessaire pour atteindre les objectifs des autres phases du musée. 


\section{Mots clés}

Publication sur le Web ; expositions interactives ; multimédia ; musées virtuels ; patrimoine ;

Reynolds Pombo

Pesquisa-criação, geradora de conhecimento para a construção de um museu virtual do patrimônio científico e cultural do Dr. Jorge Reynolds Pombo

\section{Resumo}

O macroprojeto do Museu Virtual Dr. Jorge Reynolds Pombo é composto por quatro etapas; a primeira, refere-se a saber quais são as estratégias para a análise das fontes de informação das obras, logs e objetos de pesquisa desenvolvidos pelo Dr. Jorge Reynolds Pombo, para sua divulgação em um Museu Virtual. Com base nisso, uma estrutura referencial é estabelecida na identificação de elementos virtuales, de catálogo, de museu e de patrimônio cultural e científico; aspectos que levaram à geração de ferramentas de coleta de dados baseadas em aplicações tecnológicas e, com esses dados, organizando e apresentando as informações documentais para determinar as coleções que serão a estrutura do museu virtual. A continuidade é necessária para alcançar os objetivos das outras fases do museu.

\section{Palavras-chaves}

Publicação na Web; exposições interativas; multimídia; museus virtuais; herança; Reynolds Pombo

Tapui purii- rurai kaiarigta kai wasi musiu kawachinga kagta paipa kagta i suma Achka iuiaspa i kai atun suma iuiaiug runa suti kagta Dr. Jorge Reynolds Pombo

\section{Maillallachiska}

Kaisi atun tsabaju katichii musiupi kai atun iuiaiug runa suti Jorge Reynolds Pombo, kaiarimmi nispa chusku tsabajai kagta; sug kansi kasa, niriami rigsingapa ¿kaikansi kamkuna kai tsabajukuna kai atun iuiaiug runa Jorge Reynolds Pombo, kai ruraikuna imasami tapurirka kai musiupi kawachingapa? Chi kansi kaiariska maskai kai ñugpa tsabajukunapi; chasaiatata antiwamandata ruraspaka kutirimi chi tsabajuiatata chi kawachingapa tsabaju ruaska, maitukumi kagata tsabaju, kai wasi tsabajukuna tiagta i imasami munari i kuriari kimkimpa tsabaju imasami kilkaska tiaskamanda, ña kai Tukui iukaspaka allichirimi kawachingapa chi wasisuma musui sitipi; chasa misistirimi chasaiatata katichingapa imasami kai, ruraikuna kai sug tsabajukunasina chi atun wasi musi suti kaskapi.

\section{Rimangapa Ministidukuna}

Rimanakudiru kan musu timpupi kumputadur suti makinaña; kawachirispa sugkunata; ashaka tsabaju tiaskap; sug atun wasi musui suti; kawachirikapi; paipa kaska; Reynold Pombo 


\section{Introducción}

La idea del presente macroproyecto nace en el 2014, por interés de académicos de la Fundación Universitaria del Área Andina, e inspirada en los aportes científicos, académicos y la admiración al Dr. Jorge Reynolds Pombo, científico colombiano, quien ha desarrollo procesos significativos para la humanidad y además posee un legado cultural y artístico (Imagen 1). Es así, que se empieza a dar forma, a la idea de divulgar y difundir el patrimonio científico y cultural del Dr. Reynolds.

La Unesco, e ICOM (Consejo Internacional de Museos) en el 2007, durante la 22ª Conferencia general de Viena (Austria) definió museo como "...una institución permanente, sin fines de lucro, al servicio de la sociedad y abierta al público, que adquiere, conserva, estudia, expone y difunde el patrimonio material e inmaterial de la humanidad con fines de estudio, educación y recreo.", (Museos, 2015). Esta definición soporta la decisión de construir un museo virtual, conservar, exponer y difundir el patrimonio científico y cultural para propósitos de estudios, educar y entretener, y a partir de la inclusión de las Tecnologías de la Información y la Comunicación (TIC), con la virtualidad, como herramientas, técnicas y medio de difusión y accesibilidad, para construir sociedad de conocimiento e interacción de comunidades (UNESCO, 2005).

Con base en lo anterior, se estructura el macro proyecto de gestionar y divulgar el patrimonio científico y cultural del Dr. Jorge Reynolds, el cual se planifica en 4 fases:

1. Estrategias de análisis de fuentes de información del patrimonio cultural y científico del Dr. Jorge Reynolds Pombo.

2. Las redes semánticas como constructoras relacionales de los contenidos temáticos en las colecciones para el Museo Virtual Jorge Reynolds Pombo.

3. La comunicación visual y la hipermedia para la edición y producción de las obras que harán parte de las colecciones del Museo Virtual.

4. Diseño de la arquitectura de información y visualización para la web de las colecciones del Museo Virtual.

El Museo Virtual Dr. Jorge Reynolds Pombo, tiene como misión realizar exposiciones en línea, virtuales

1 Código proyecto de Investigación CV2015-073, Dirección Nacional de Investigación, Fundación Universitaria del Área Andina, Grupo de investigación Proyecta

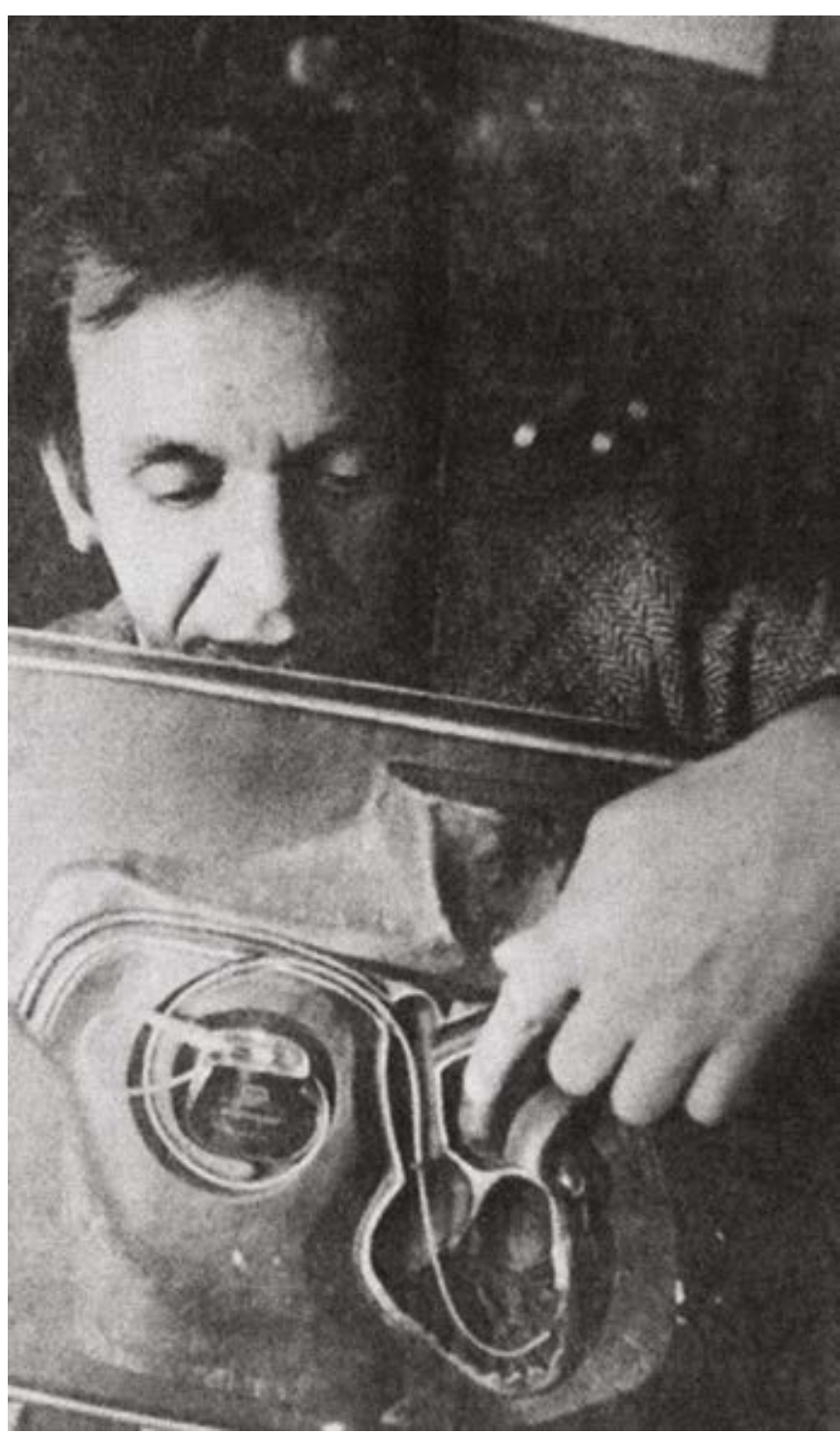

Imagen 1. Dr. Jorge Reynolds Pombo. Fotografía tomada y retocada de la colección personal de recortes de prensa Dr. Jorge Reynolds Pombo.

e itinerantes, divulgar, difundir y promover el diseño de materiales con contenidos análogos y digitales del patrimonio científico y cultural del Ing. Jorge Reynolds Pombo, con el propósito de orientar a una diversidad de públicos en el desarrollo educativo, social y cultural sobre los aspectos científicos y culturales de su legado. Por su parte, la visión se enmarca como un escenario para contribuir a los procesos de educación no formales, formales culturales mediante la exposición de obras digitales y materiales con contenidos análogos y digitales, de las temáticas en torno a la invención del marcapasos externo, las mariposas de Francisco José Caldas y el legado literario de los Pombo, convirtiéndose en un referente de consulta y apoyo educativo que contribuya a la generación de conocimiento y al desarrollo 
de las comunidades científicas, sociales y culturales de Colombia.

Se puede visualizar el macro proyecto en la infografía de la (figura 1). Inicia con la identificación de las fuentes de información, partiendo que los objetos que harán parte de un museo se identifican como documentos, es así que se aplica a estos documentos el "proceso documental", dentro de este proceso se identifica la "fase de colecta", donde se habilita desde la fuente aquellos objetos, que van a hacer parte del fondo, cabe aclara que en esta fase, el objeto no es asignado físicamente sino por medio de un proceso de digitalización, (Fajardo, 2017), este proceso parte de la colección personal de documentos análogos y digitales, impresos, audiovisuales y de artefactos; los documentos impresos, son recortes de prensa, revistas e informativos de sus estudios, actividades científica, académica y entrevistas; consignadas en álbumes durante más de 50 años.

Ahora bien, emergen preguntas en torno a cómo identificar, organizar, y registrar esta cantidad de información, para lo cual se ejerce la curaduría, como la actividad compleja de conservación, estudio y comunicación de las obras del museo con el propósito de preservar el patrimonio, donde se colecciona, cataloga y conserva de manera ordenada y sistematizada (Colombia, 2009); nace la pregunta ¿cuáles son las estrategias para el análisis de las fuentes de información de las investigaciones del Dr. Jorge Reynolds Pombo, para la divulgación en un Museo Virtual? Para llegar a la respuesta, se fija el objetivo de diseñar estrategias para la documentación, organización, archivo, digitalización y documentación del patrimonio de los saberes, obras y objetos de las investigaciones del Dr. Reynolds, con la finalidad de conservar, estudiar y dar a conocer las evidencias a través del "Museo Virtual Jorge Reynolds Pombo, Patrimonio científico y cultural".

En esta primera fase, es importante explicar que el proyecto es insumo, como fuente de inspiración para el desarrollo de proyectos académicos en torno a la creación de contenidos para el museo virtual y el museo presencial, de programas de diseño gráfico, modas y animación y posproducción audiovisual de la Fundación Universitaria del Área Andina en un proceso de creación editorial, indumental y audiovisual para generar otros productos que aporten y apoyen las obras originales del museo. Existen otras entidades como las comunidades científicas, culturales, y académicas que pueden colaborar con estos proyectos. Es necesario la investigación, el conocer las teorías y conceptos en diferentes campos como la museología, la catalogación para inventariar y organizar los documentos, con base en la curaduría de museos y la curaduría digital. Las redes semánticas son la estrategia para relacionar los conceptos de cada una de las temáticas del museo, la electrofisiología del corazón, las mariposas del Sabio Caldas y la literatura de los Pombo; son temas que habrá que desglosar para generar un modo de lenguaje entendible para los diferentes públicos y coadyuvar a la curaduría de los contenidos y las obras que usan tecnologías de la información y la comunicación, para sistematizar, digitalizar y divulgar el patrimonio científico y cultural de los saberes y artefactos del Museo Virtual.

\section{La catalogación}

El acto de catalogar es una acción que se ha de realizar en todo espacio, donde se han de clasificar los elementos o partes constituyentes de unidades que son engranajes del todo, con la finalidad de establecer un orden lógico a las diferentes y diversas partes, en éste caso a la información, partiendo de una observación global de los elementos (documentos), para luego ir a lo particular; donde dicho proceso requiere de un ordenamiento, que da pie a la inclusión del concepto y la acción de catalogar.

Ahora es posible decir que, la catalogación es la descripción ordenada de objetos o elementos, generalmente de documentos, a partir de unos parámetros o normas. Siguiendo a Olga Quintanilla, en el curso de "Introducción a la catalogación automatizada", en el espacio, descripción bibliográfica, expresa: “La catalogación es el proceso de describir los elementos informativos que permiten identificar un documento y de establecer los puntos de acceso que van a permitir recuperarlo por el título, autor o materia, los cuales se conocen de antemano aplicando reglas ya establecidas internacionalmente" (Quintanilla, 2005).

Considerando la catalogación bibliográfica o documental; hay distintas posturas relacionadas con las acciones que se realizan para la catalogación de fuentes de información, tanto es así que para algunos autores está la descripción bibliográfica única, donde dicha tarea aglutina las operaciones pertinentes a nivel de análisis externo del documento y otros identifican la descripción bibliográfica con la catalogación y otros asumen que hay dos aspectos diferentes en la catalogación y la descripción bibliográfica que hace ver dos diferentes acciones y por lo tanto son independientes (Garrido, 1996). 


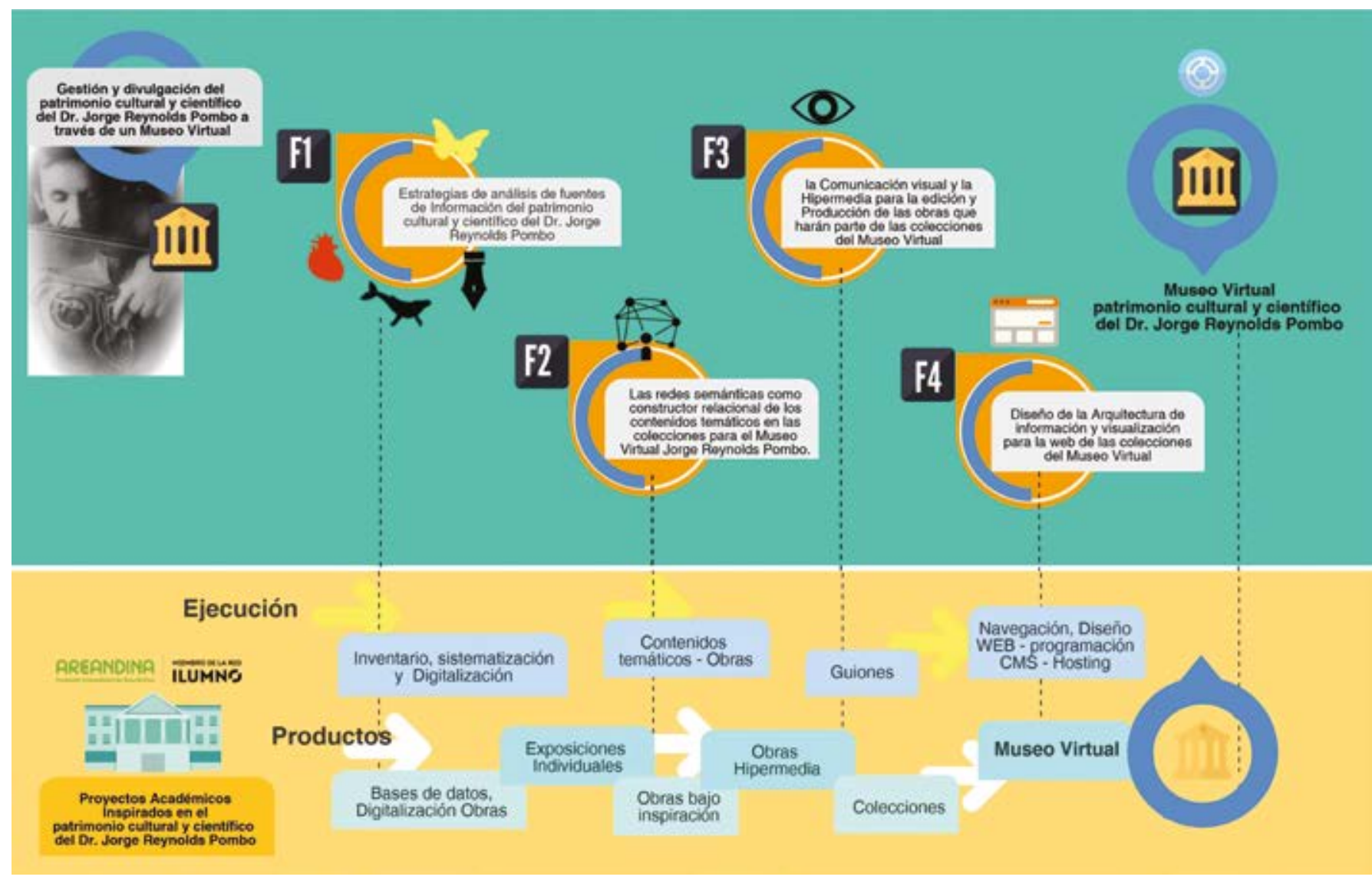

Figura 1. Infografía Macro proyecto Conservación, exposición y difusión del patrimonio cultural y científico del Dr. Jorge Reynolds Pombo en un Museo Virtual. Elaborada por: William Ruiz Joya. Investigador principal: William Ruiz. Coinvestigadores: Héctor Córdoba, Olga Lucia Zipa y Facultad de Diseño, Comunicación y Bellas Artes.

Cutter, presenta una postura, la cual es citada por Garrido (1996), donde: el catálogo es el componente bibliográfico por excelencia, cuyos objetivos han sido repetidos con algunas variaciones no significativas en las diferentes culturas, no hay hasta ahora otra fuente original para conocerlo; acá, Cutter afirma que el primer objetivo del catálogo es facilitar la ubicación o localización de un libro o documento, del que se identifica el autor, título o materia, por lo tanto en términos de Cutter, "La catalogación, es el proceso de elaborar un catálogo".

Atherton, también citado por Garrido, define la catalogación como el "proceso mediante el cual se transfieren, conforme a determinadas reglas, a un registro bibliográfico ciertos datos informativos de un documento" (Garrido, 1996).

Entonces, la catalogación es un proceso que parte de la descripción del documento, pasa por la elección de puntos de acceso como datos personales, corporativos, títulos, temáticas y autores y se completa con el asiento, es decir, con la transcripción de datos y el correspondiente registro.

\section{La catalogación digital}

La utilización de las tecnologías de la información y la comunicación, en la puesta en escena de la literatura científica, abren un sinnúmero de posibilidades para la comunidad académica o sociedad del conocimiento; una amplia gama de recursos, los cuales hacen que cada vez se requiera una inversión de tiempo significativa para la consulta, evaluación y aprovechamiento de la información disponible en los medios informáticos, de tal manera que, se hace complejo seleccionar la información que se considere relevante para la temática en cuestión (Torres, 2006). Así que es vital el desarrollo de un guion curatorial, bien lo define Carlos German Gómez, en la revista INAH, "como un instrumento técnico que contiene las líneas generales de la idea que da coherencia al conjunto expositivo y muestra las posibilidades temáticas en que se puede desarrollar esta idea mediante el espacio de exhibición" (López, 2013)

Ahora que se toma a Internet, como la fuente de consulta globalizada, se han desarrollado y perfeccionado las herramientas que apoyan a los cibernautas en 
el proceso de búsqueda de información en la red de redes. Herramientas como los buscadores tipo directorios, los motores o robots y los metabuscadores, entre otros, han evolucionado e incorporado a los sistemas opciones sofisticadas de búsqueda de interfaces amigables.

De otra parte, la variedad de herramientas no es la solución al problema, ya que dicha problemática, va más allá del proceso de búsqueda de la información; los documentos en la Web no han sido diseñados con base en esquemas organizados de la información, a diferencia de los materiales impresos, este evento hace difícil la descripción y organización y, por ende, el resultado de la búsqueda y recuperación de la información.

Entonces, dado el incremento de los servicios en línea y la disponibilidad de los documentos virtuales, creados en espacios en línea y basados en el hipertexto, hace que se reconozcan sus particularidades en el campo de la descripción de los documentos y que se pierden en la recuperación de la información, y es por esta razón, que se ha desarrollado la estructura del metadato que actualmente tiene vida y fuerza en la clasificación de fuentes de información.

\section{El museo}

Los museos han evolucionado con la historia de la humanidad, como muchas otras instituciones sociales, ha modificado sus funciones y los principales conceptos sobre los cuales fundamenta su quehacer. “El museo es una institución permanente, sin fines de lucro, al servicio de la sociedad y de su desarrollo, abierta al público que adquiere, conserva, estudia, expone y transmite el patrimonio material e inmaterial de la humanidad y de su medio ambiente con fines de educación y deleite". (ICOM, 2009).

A continuación, se presentan algunos conceptos generales en materia de museología:

- Colección: Son grupos de bienes culturales y singulares que se relacionan con una intencionalidad y temática específica. Burcaw (1997) lo define como “los objetos de museo colectados, adquiridos y preservados en razón de su valor ejemplar, su valor de referencia o como objetos de importancia estética o educativa".

- Curaduría: Actividad compleja de conservación, el estudio y la comunicación de las obras del museo con el propósito de preservar el patrimonio, donde se colecciona, cataloga y conserva. (Colombia, 2009)

- Exposición: “Este término designa a la vez el acto de presentación al público de ciertas cosas, los objetos expuestos y el lugar donde se lleva a cabo esta presentación" (Davallon, 1995).

- De acuerdo con Salazar (2012), existen diferentes tipos de exposición:

- Exposiciones temporales: Son exposiciones de una duración corta, que puede ir desde un mes a tres meses, aproximadamente.

- Exposiciones itinerantes: A diferencia de la exposición temporal, la itinerante está concebida para viajar e instalarse en diferentes sedes.

- Exposiciones permanentes: Por lo regular son exposiciones de colecciones de museos, y su duración es prolongada. En ellas los movimientos de obras y los cambios en el montaje pueden suceder a partir del cuarto año, o de un periodo mayor.

- Las exposiciones son la acción fundamental de difusión de cualquier museo y la aparición de las tecnologías de la información y la comunicación (TIC), ha permitido una nueva dimensión narrativa y comunicativa y, en consecuencia, una nueva manera de generar el discurso expositivo, lleno de posibilidades y abierto a la experimentación (Solanilla, 2002).

- Objeto (de museo): En una exposición, los "objetos" son presentados como el resultado de un conjunto de testimonios materiales creados por los individuos en un determinado espacio, contexto y tiempo, son considerados también como los signos con los cuales se construye un discurso que se puede presentar, para educar, emocionar y entretener al público.

\section{Los museos virtuales}

Los museos virtuales son entornos con recursos didácticos, donde se puede adquirir conocimiento a partir de la observación de lo natural, histórico, artístico, científico, tecnológico, por nombrar solo algunos campos; dan paso a la interactividad, haciendo que dichos espacios permitan la familiarización con el patrimonio, el cual es posible aumentar, desde las nuevas visiones de la comunicación multimedial y de masas.

El museo tiene la característica de poseer una doble responsabilidad, por una parte, conservar y preservar la identidad del objeto u obra, como elemento o componente del patrimonio, y por otra, contribuir a la difusión y evolución del conocimiento, a través de la 
investigación y al proceso de enseñanza-aprendizaje, como apoyo a la formación y educación del ser humano.

Santibáñez cita a Mackenzie, quien expone:

Se define el museo virtual como una colección de artefactos electrónicos y recursos informativos de todo aquello que pueda digitalizarse. Pueden incluirse pinturas, dibujos, fotografías, videos, textos, gráficos, imágenes, bases de datos; es decir, un conjunto patrimonial de información y de objetos que pueden ser guardados en un servidor de un museo virtual (Santibáñez, 2005).

Dicho espacio virtual busca generar la actividad mental y emocional del usuario o visitante, mediante la interacción e intervención, donde es posible encontrar un chat o un foro de discusión; las distintas actividades interactivas por realizar en los diversos tipos de museos, da respuesta a la realidad de la cultura y de la ciencia, como a los gustos, preferencias, intereses y necesidades de los cibernautas (Santibáñez, 2005).

\section{Tipología y características de los museos virtuales}

Piacente, en 1996, presenta una clasificación de los museos virtuales, que, de acuerdo con la tipología, distingue tres tipos de páginas web. El primer tipo o categoría es el folleto electrónico, expuesto de otra manera, es el formato publicitario o de propaganda como los folletos presentados en la promoción del museo. El segundo tipo es el museo en el mundo virtual, es lo mismo decir que es la puesta en escena del museo físico en el ambiente virtual, con la presentación de planos, información de colecciones, exhibiciones y exposiciones en línea. La última categoría está dada por los museos virtuales verdaderamente Interactivos (valga la mayúscula I, para resaltar la acción, ya que no todo lo que se muestra en el mundo virtual es interactivo), donde tiene relación en algunos espacios con el museo físico y también se adicionan elementos o artefactos electrónicos, involucrando a los usuarios en actividades interactivas (Virtual \& Virtual, 2011).

\section{El patrimonio cultural y científico}

Ahora, se hace necesario establecer las distinciones desde las cuales se operacionaliza el manejo de la información básica, para la estructuración del museo virtual; por lo tanto, Patrimonio se refiere al conjunto de bienes propios o heredados, que tiene un valor espiritual o económico, y que se desea preservar en las generaciones, estos objetos pueden ser tangibles, perceptible a la vista y material e intangibles, que no es material también llamado inmaterial, la Unesco lo describe como patrimonio cultural inmaterial, la Unesco determina la importancia del patrimonio cultural inmaterial en que "no estriba en la manifestación cultural en sí, sino en el acervo de conocimientos y técnicas que se transmiten de generación en generación" (Unesco, n. d.). Este patrimonio inmaterial, depende de los conocimientos, tradiciones y técnicas trasmitidas por comunidades y comprende tradiciones orales, artes del espectáculo, usos sociales, rituales, actos festivos, conocimientos y prácticas relativas a la naturaleza y el universo, y saberes y técnicas vinculados a la artesanía" (Unesco). Es significativo anotar que después de la segunda guerra mundial, para proteger la cultura de los pueblos, con base en la destrucción y pérdida de patrimonio, se establecieron protocolos de protección del patrimonio con la aprobación de la convención para la protección de bienes culturales en caso de conflicto armado, firmada el 14 de mayo de 1954.

Igualmente, existe el patrimonio científico, que describe a la actividad científica y técnica, como resultado de la investigación o la enseñanza, los objetos producto de investigaciones, así como los procesos, teorías y modelos, son parte del acervo del conocimiento. Se puede clasificar el patrimonio en; patrimonio escrito, determinados por manuscritos, documentos escritos impresos, y escritos magnéticos desde el inicio de la era digital. El patrimonio grabado, refiere a registros como la fotografía, los films, videos, hoy en día la hipermedia, y finalmente el patrimonio de objetos y construcción. Llamado de tres dimensiones, y refiere a los inmuebles, instituciones, obras de artes, artefactos y las habilidades del hacer y saber de la ciencia (Rosell, 2000).

Para concluir este tema, el patrimonio tiene unos valores, como la memoria, la capacidad de evocación, el acceso y la transmisión de información, la conservación de los bienes materiales e inmateriales, el aporte histórico, y el valor educativo, son valores ineludibles. Ahora bien, es necesario desarrollar estrategias para la conservación, recopilación, registro, inventario y difusión para preservar la autenticidad del patrimonio científico y cultural, para éste estudio de los saberes y objetos del Dr. Jorge Reynolds Pombo (García Cuetos, 2012). 


\section{Legado cultural y actividad científica del Dr. Jorge Reynolds Pombo}

Los componentes del patrimonio cultural se enmarcan en el árbol genealógico de la familia Reynolds Pombo, desde el linaje Pombo; en la literatura en especial, en su relación y legado de Rafael Pombo, poeta conocido por sus fábulas. Y también, un legado no filial, con el Sabio Caldas, cuya colección de mariposas (hace más de 200 años) hoy se encuentran al cuidado del Dr. Reynolds. Durante los últimos 60 años, el Dr. Reynolds ha desarrollado aportes a la humanidad en investigaciones del corazón, a partir de estudios realizados en mamíferos (ballena, delfín, entre otros), estudiando electrocardiográficamente a deportistas por telemetría y con expediciones al Himalaya, dando como resultado la creación del primer marcapasos externo en 1958; hoy en día, realiza trabajos para la creación del nano marcapasos. Es extensa la lista de sus obras que determinan el patrimonio científico y cultural, que hacen parte del legado a la humanidad, por esto es importante construir el Museo Virtual.

\section{Metodología}

El macroproyecto del Museo Virtual, en la primera fase denominada: "Estrategias para el análisis de fuentes de información del patrimonio cultural y científico del Dr. Jorge Reynolds Pombo para un museo virtual", ha sido abordada desde varias disciplinas como la museología, las TIC, la comunicación visual, la informática; la básica es la investigación documental, ya que se ha de recopilar, analizar y seleccionar los datos de los diferentes documentos producidos en la labor científica y el legado de Reynolds Pombo, para luego estudiar la información, recopilar y registrar para el museo virtual.

Las ciencias sociales utilizan la investigación documental para generar su conocimiento, la investigación documental de cierta manera es un proceso que toma la información de una fuente secundaria; siempre y cuando dicha fuente haya sido generada por la interpretación de personas las autoras o no de dicha información. La información de la investigación documental, es posible encontrarla en espacios bibliográficos, hemerográficos o archivísticos; la primera se basa en la consulta de libros, la segunda en artículos o ensayos de revistas y periódicos, y la tercera en documentos que se encuentran en archivos como cartas oficios, circulares, expedientes, ya sean de carácter público o privado (Gómez; Grau; y otros, n. d.).
Siguiendo a Alfonso (1995) citado por (Morales, 2008), la investigación documental es un proceso que busca información, basado en la indagación, recolección, organización, clasificación, análisis e interpretación de datos de un tema determinado, el cual tiene el propósito de contribuir con la generación de conocimiento; lo cual hace que se constituya en un procedimiento científico.

Otra particularidad de la investigación documental es utilizar como fuente primaria los insumos obtenidos de documentos, llámese documentos a la información consignada en diferentes tipos y formatos escritos, electrónicos y audiovisuales. Sin embargo, es posible recurrir a otras fuentes como, por ejemplo, el testimonio de los protagonistas de hechos, de testigos calificados, o de especialistas en el tema, motivo de consulta o de indagación (Morales, 2008).

Ahora bien, de acuerdo con Galán, el concepto de documento es amplio, ya que alberga materiales como diapositivas, películas, planos, discos y todo el material digital que es posible consultar en la web y que en algunos espacios es documentación temporal y de alguna profundidad; en este concepto vale la pena contrastar la información, de tal manera que hay que generar la certeza de lo consultado, para poder asirse de la interpretación, para la divulgación idónea de lo que se da a conocer o se expone a la sociedad del conocimiento (Galán, 2011).

La elección de los instrumentos para la recopilación de información ha de reunir condiciones de fiabilidad y objetividad documental. La técnica documental tomada - elegida ha de permitir la recopilación de información desde la cual se pueda enunciar las teorías que sustentan el estudio de los fenómenos y procesos a estudiar (Galán, 2011).

Con los avances tecnológicos, la expansión e impacto de las comunicaciones en la red ha generado la identificación de una nueva sociedad; la sociedad virtual. Donde su hábitat ciberespacial y el tiempo virtual, hacen que se conciba un nuevo fenómeno a estudiar y conceptualizar, cuyos componentes se encuentran para ser explorados, pues su puesta en escena es motivo y objeto de estudio, dada la interacción que se realiza en el mundo de lo intangible. Acá, nacen interrogantes que permiten abrir las ventanas de la globalización, a dichos cuestionamientos da respuesta Galán, y expresa: "¿Qué es la webgrafía? es un directorio de aplicaciones y recursos libres, puede seleccionar una categoría y explorar los diferentes recursos. ¿Cuáles son las categorías? Actualmente se cuenta con 21 recursos 


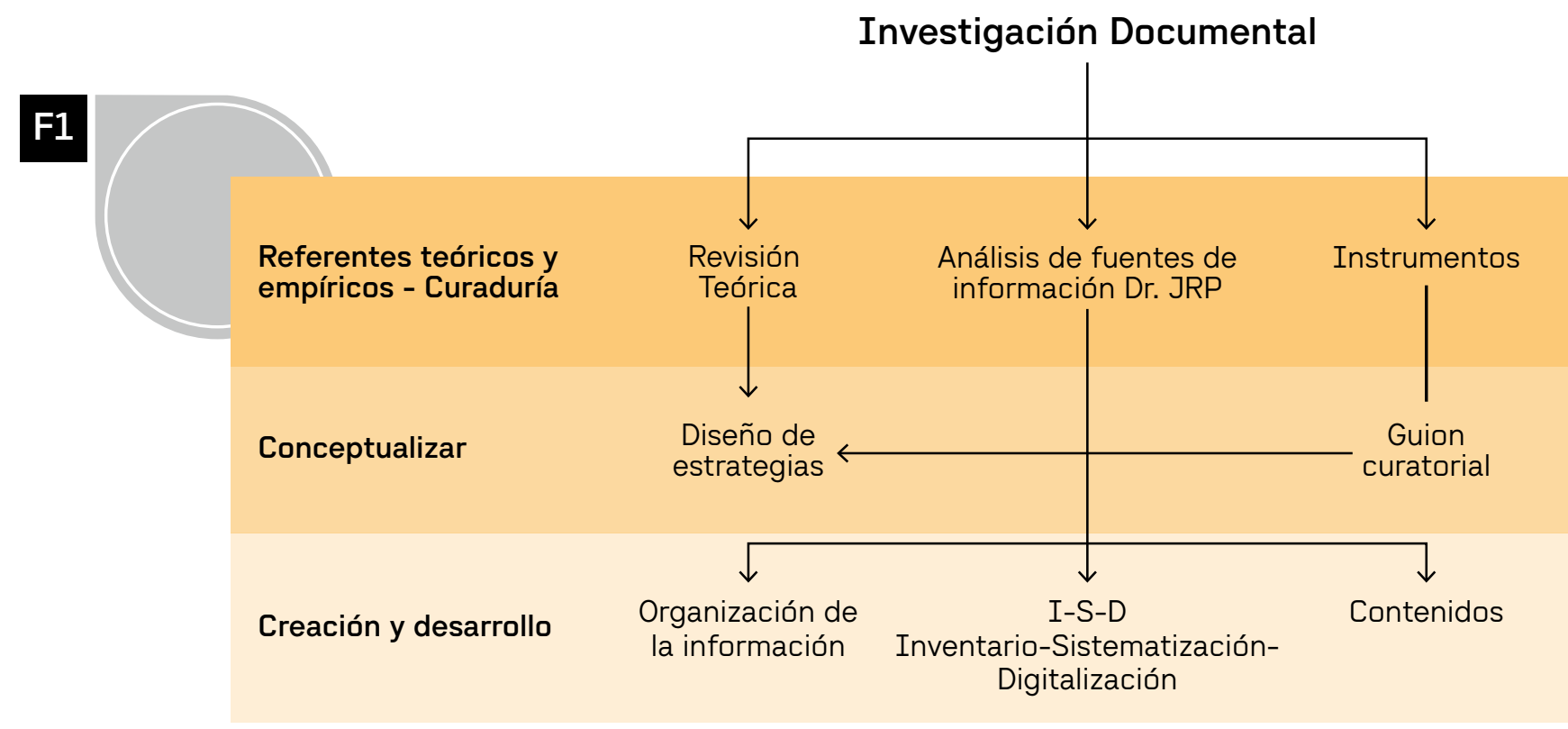

Figura 2. Ciclo metodológico para el desarrollo de la primera fase.

distribuidos en las siguientes 17 categorías Redes, Oficina, Multimedia, Desarrollo, Matemáticas, Juegos, Técnicas, Gráficos, Educación, Ciencia, Ingeniería, Bases de datos, Sistemas operativos, Escritorio, Seguridad, Utilidades, entre otros. ¿Cuáles son los tipos de recursos? En este momento se clasifican los tipos de recursos en tres: Programas, Documentos y Enlaces, en el caso de programas y documentos no se encuentran al interior del portal, de hecho, el directorio solo organiza, clasifica y enlaza los recursos (Galán, 2011).

Existe una fase exploratoria, donde se consulta la documentación desde diferentes campos, como la museología, las tecnologías y la comunicación; así como la fuente primaria, que en el ciclo metodológico se denomina referentes teóricos y empíricos. Luego, se va a una fase descriptiva, se determina la situación del patrimonio científico y cultural, con base en los documentos registrados, estas fases cuentan con instrumentos de recolección de datos.

\section{Trabajo de campo, registro fotográfico, digitalización y tratamiento de imagen}

El trabajo de campo se realiza desde el mes de abril del 2015, durante el cual se tuvo acceso a documentos fuente para la investigación, que son álbumes de recortes de prensa y elaborados por el Dr. Jorge Reynolds, que se encuentran en la oficina de la Clínica Shaio, en la ciudad de Bogotá. Se usaron instrumentos de recolección de datos, diseñados para: organizar, registrar e inventariar, para sistematizar y digitalizar la información documental, la técnica utilizada es la observación y uso de un formato con los componentes de catalogación para documentos, los cuales contienen cuatro categorías: a) Identificador de documento, b) Identificador del medio del documento. c) Identificador de la fuente y d) Visualización del documento.

La información contenida en los álbumes, evidencia una clasificación significativa para cada uno de los recortes de prensa de los principales medios impresos a nivel nacional e internacional, estableciendo una cuidadosa línea de tiempo con el trabajo y avances científicos registrados durante los años de 1958 a la actualidad. Teniendo en cuenta la trascendencia de esta información, el grupo de investigadores hace un registro fotográfico al álbum número uno de aproximadamente, trescientas noventa fotografías, paralelo a este ejercicio se realiza registro del material en un primer formato, teniendo en cuenta aspectos: número de recorte, álbum, página de álbum, año, mes, nombre del medio, título del reportaje. Este proceso generó un nuevo instrumento en una base de datos digital, permitiendo clasificar los medios de carácter científico y los de interés general; reconocer los temas transversales del trabajo científico y cultural, como, por ejemplo: la medicina en 

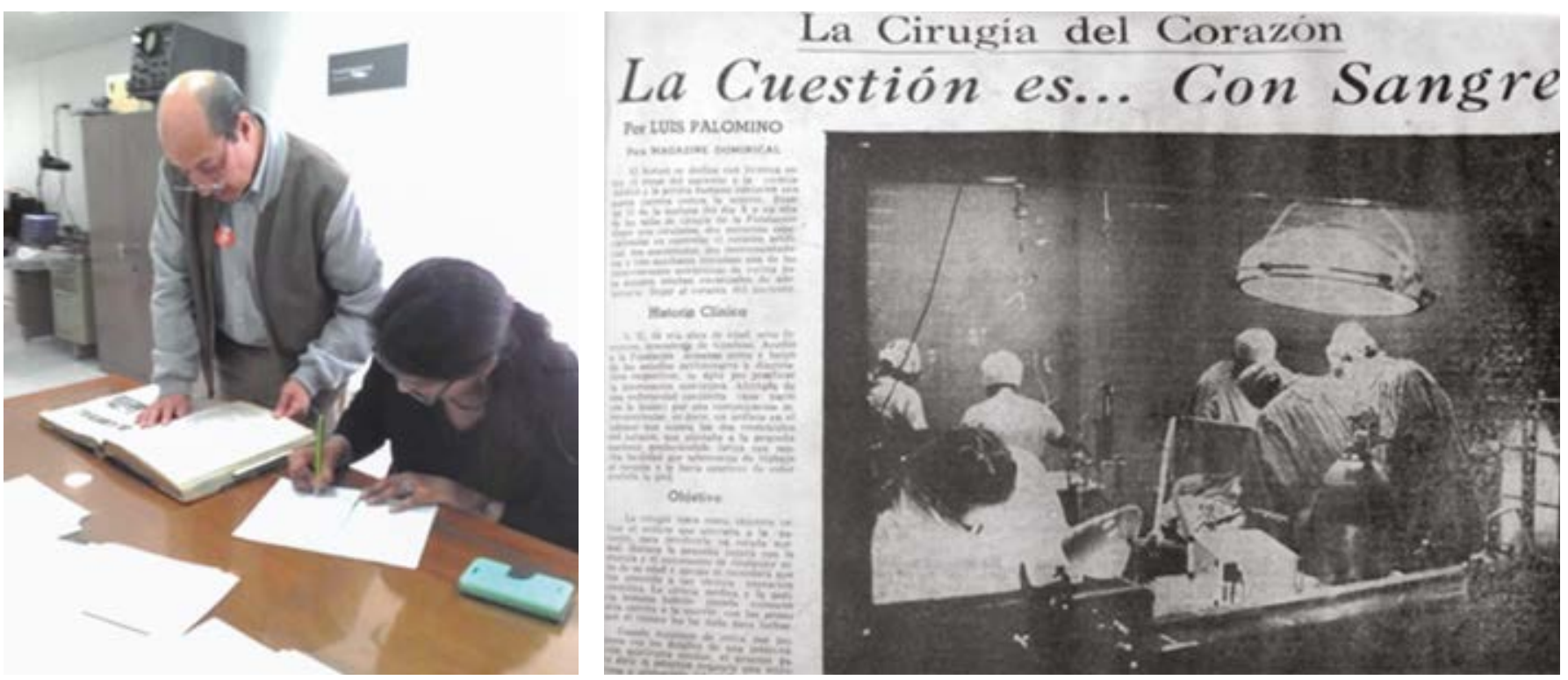

Imagen 2. Recolección de datos e imagen digital tratada

Colombia, la cardiología, el marcapasos, los avances en electrocardiogramas, el corazón de la ballena, entre otros. Hasta la fecha se han registrado dos mil ochocientas fotografías que corresponden a cuatro álbumes.

Con la intención de preservar, del paso del tiempo, el legado cultural del Dr. Reynolds; las manchas, el sustrato (papel) y el tipo de impresión, entre otros, que deterioran los recortes de prensa, se ha realizado una digitalización a partir de fotografías del material análogo, este proceso no se podía hacer por escáner debido a las características físicas de los álbumes y el estado de los recortes de prensa. Las fotografías que se obtienen de los recortes de prensa necesitan ser ajustados, porque al pasar del papel a un archivo digital sus elementos gráficos (texto-imágenes) se muestran distorsionados y los colores cambian. Es así que se realiza un tratamiento de la imagen realizada con un software para este fin, que ayuda en gran medida a corregir estos problemas y mejorar la legibilidad de los textos.

Para lograr una mejor calidad y recuperar los colores que más se acercaran al original (prensa de la época), fue necesario trabajar con equilibrio tonal y los niveles de los distintos pixeles para controlar el grado de luminosidad de la imagen. Además, se consiguió optimizar la resolución de las imágenes para que se visualizara bien en pantalla y en impresión para realizar una futura exposición. Continuando con el tratamiento digital de los recortes, se procede a generar una plantilla digital con el propósito de mantener un mismo criterio para la presentación de la información y su posterior ingreso en la base de datos.

\section{Integración de la investigación con la formación, procesos educativos. Integración del proyecto con el aula}

\author{
"Ustedes pueden ser el comienzo de la parte artística \\ de la ciencia y la tecnología". \\ Dr. Jorge Reynolds Pombo, 2015.
}

El proceso de desarrollo del conocimiento es básicamente el aprendizaje y la actividad de "conocer", un desafío intelectual permanente que parte de la preocupación de los seres humanos por conocer el mundo y las cosas que le rodea. Este ha sido el fundamento del trabajo científico del Dr. Jorge Reynolds y es también un propósito institucional:

Desde los lineamientos educativos y pedagógicos la actividad investigativa está orientada a constituirse en la esencia de la vida académica y ser elemento dinámico del currículo, como espacio para la reflexión, discusión, análisis e intercambio de conocimiento, a incentivar la formación 


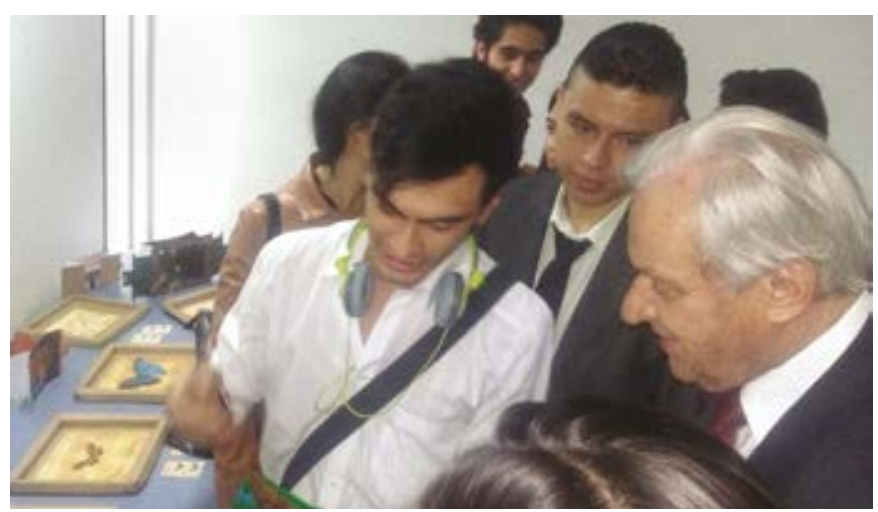

investigativa en docentes y estudiantes, a consolidar grupos y líneas de investigación y a establecer mecanismos para la socialización y difusión de la producción científica. (Andina, 2012)

Este proyecto institucional busca promover la participación y la construcción de un nuevo conocimiento a partir del legado cultural y científico del Dr. Jorge Reynolds Pombo.

Para este propósito el grupo de investigación plantea una estrategia de recopilación, análisis, catalogación y producción de nuevos objetos interpretados desde la disciplina del diseño para la divulgación del conocimiento y trabajo desarrollado por el científico colombiano. La cultura de la investigación se fortalece a partir del trabajo en grupo y la inter y transdisciplinariedad, por esta razón se vincula a estudiantes y docentes de la facultad en este proyecto.

En los procesos de investigación desarrollados, los estudiantes han participado activamente haciendo posible que se cumplan los objetivos destinados al aprendizaje y desarrollo de las competencias básicas desde su formación investigativa, los proyectos pedagógicos de aula y su vínculo con los semilleros de investigación. “El Proyecto Pedagógico de Aula propende por un espacio que favorezca la consolidación de competencias con relación a la formación investigativa tanto para los docentes como para los estudiante" (Andina., 2012).

Es así como se vinculan las asignaturas de Edición e ilustración, video y sonido, piezas publicitarias y empaques del programa de Diseño Gráfico que han desarrollado sus proyectos de aula inspirados en las temáticas del Museo Virtual Dr. Jorge Reynolds Pombo. A partir del trabajo interdisciplinar el grupo de séptimo semestre del programa de Diseño de Modas, trabajó su proyecto en Alta Moda inspirado en la Colección Mariposas
Imagen 3. Encuentro estudiantes de la Facultad de Diseño, Dr. Reynolds Pombo.

del Sabio Caldas, que pertenece al Dr. Jorge Reynolds Pombo. Como parte del trabajo realizado dentro del proyecto, se vincularon también docentes y estudiantes a través del semillero de investigación Punto $D$, del programa de Diseño Gráfico quienes han desarrollado procesos académicos y de aprendizaje, adquiriendo unas competencias investigativas y de diseño que les ha permitido participar en eventos institucionales, encuentros y jornadas de investigación.

\section{Productos, resultado de investigación- creación, obras para el museo virtual}

Los resultados del proyecto, se deben presentar desde los siguientes aspectos: a). Resultados propios del proyecto "Estrategias para el análisis de fuentes de información del patrimonio cultural y científico del Dr. Jorge Reynolds Pombo para un museo virtual", en este aspecto, se definió el estado actual de la documentación del patrimonio científico y cultural, clasificado en el patrimonio escrito, grabado y de objetos; se puede señalar que se tuvo acceso a una colección personal de recortes de prensa, revistas y material impreso, realizado por el Dr. Reynolds, organizado en 7 libros de contabilidad (álbumes), esta es una de las primeras fuentes documentales para la investigación. De igual manera, se obtuvieron documentos audiovisuales, patrimonio grabado, así como información en la web, como también los objetos, productos científicos y culturales resultado de investigación o legado familiar. (Imagen 4).

Organizar esta gran cantidad de información, precisó desarrollar un sistema gestor de base de datos, para poder manejar y almacenar la gran cantidad de información, así como para gestionar, sistematizar y relacionar todos los datos. La forma de generar esta base de datos, se concentra en un formulario realizado con 

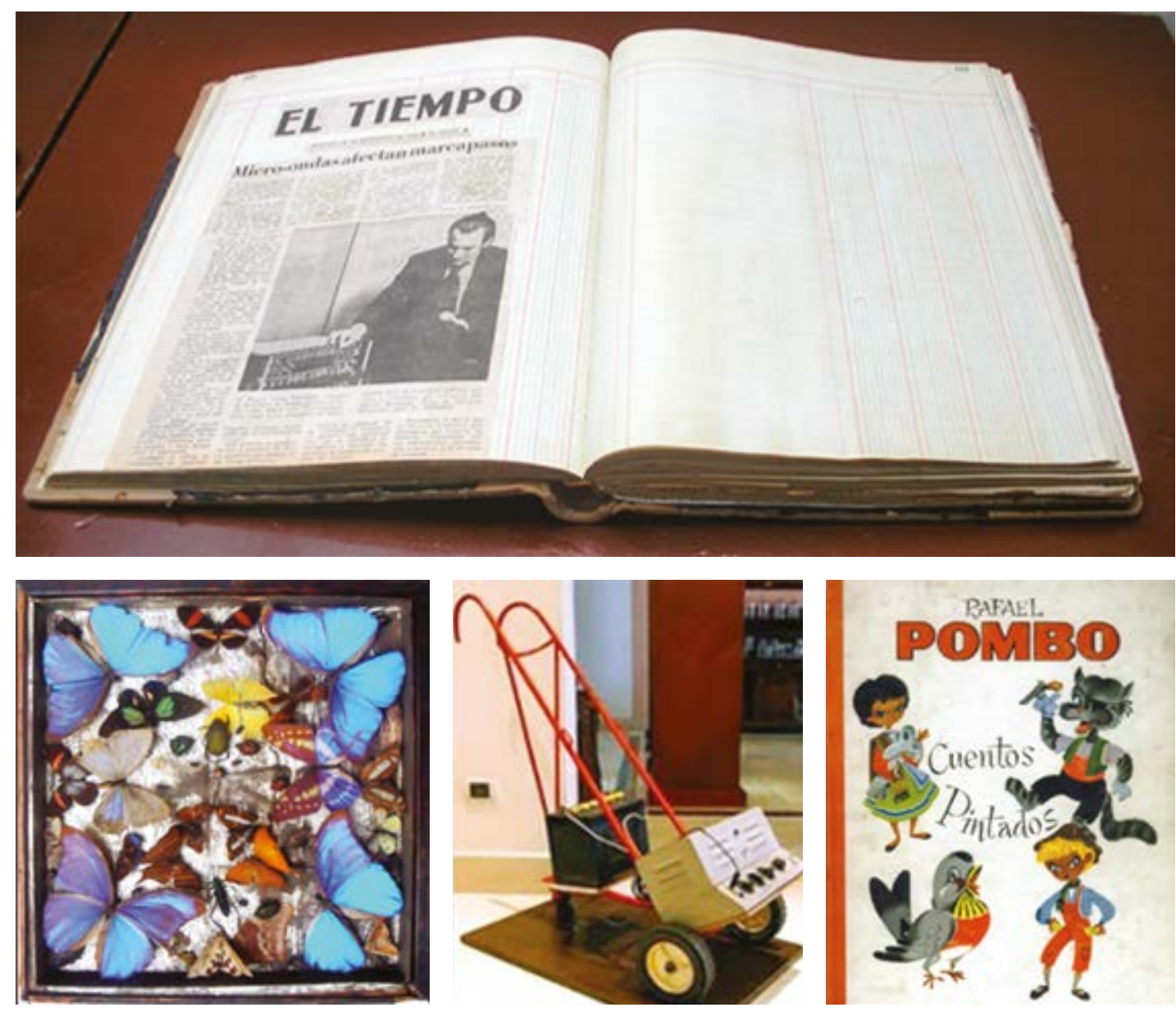

Imagen 4. Documentos patrimonio científico y cultural: álbum de recortes de prensa, mariposas del Bicentenario, primer marcapasos y libro de cuentos de Rafael Pombo.

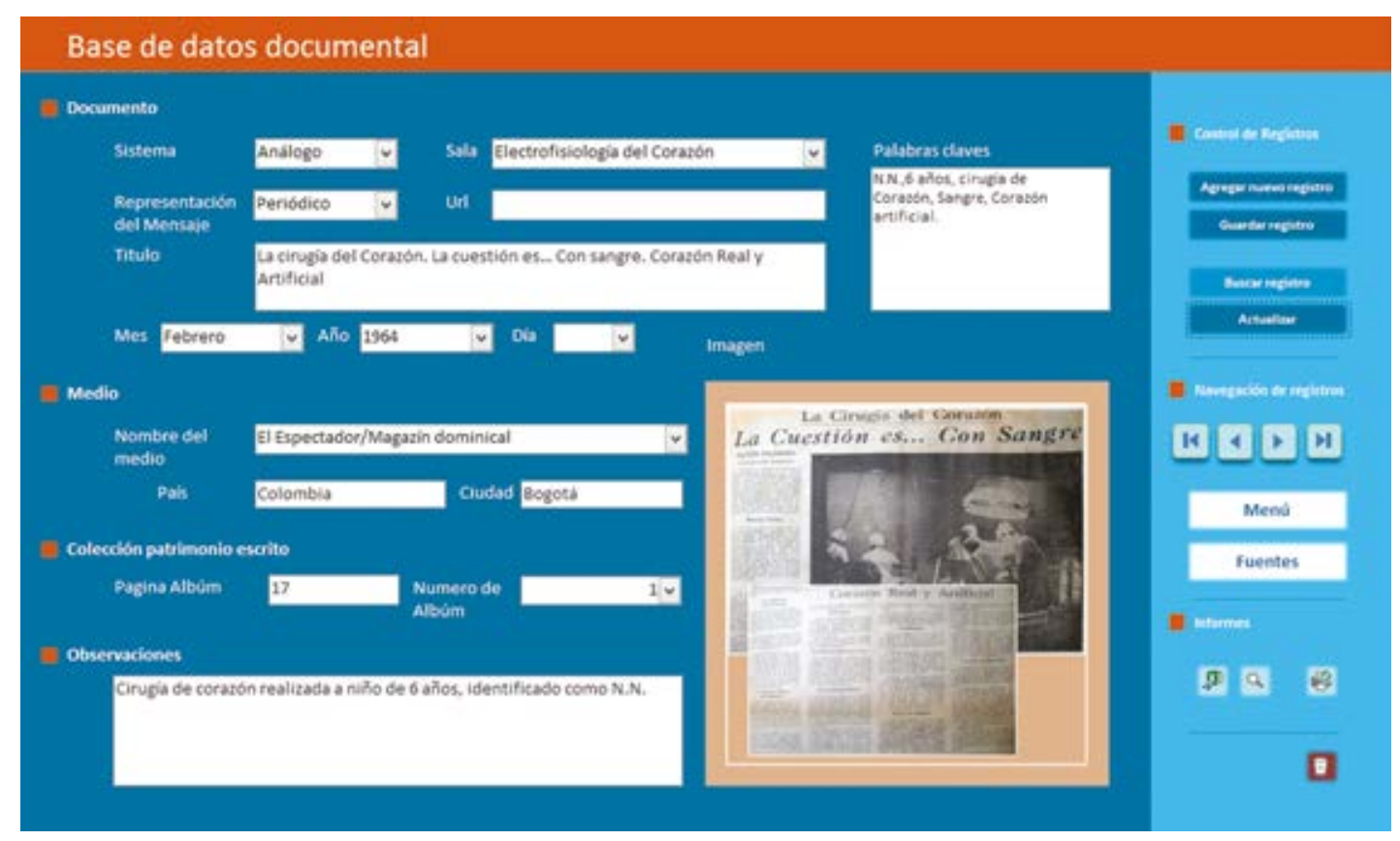

Figura 3. Interfaz base de datos. 

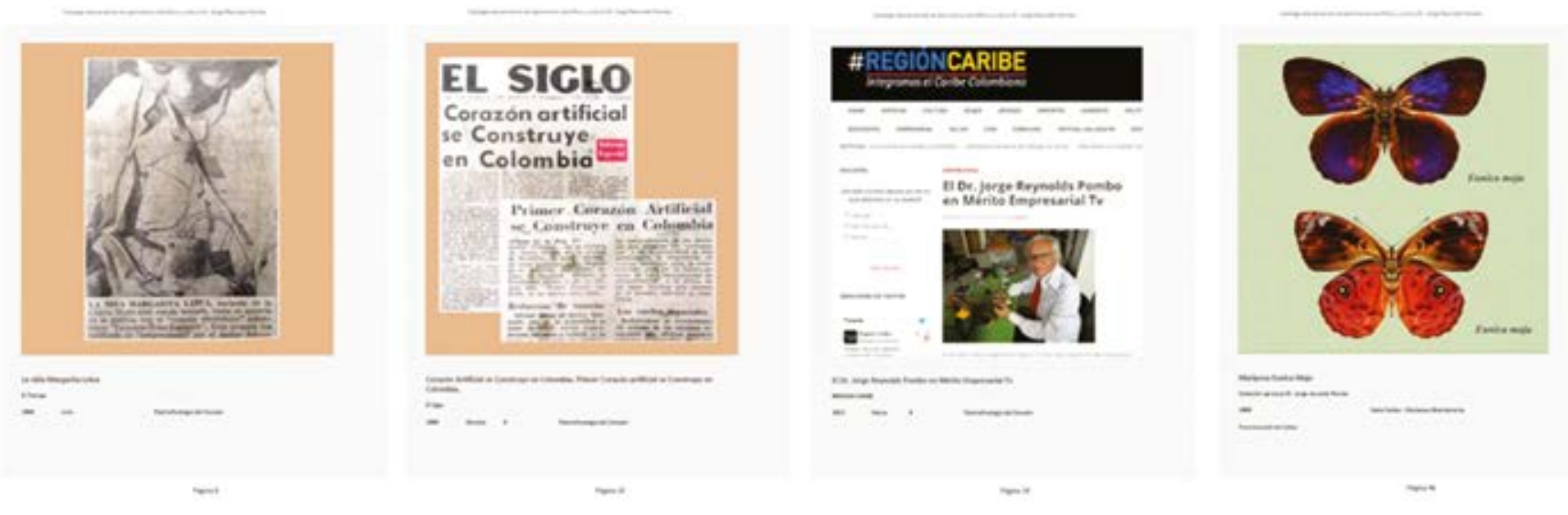

Imagen 5. Paginas catálogo de recortes de prensa, web y objetos de patrimonio.
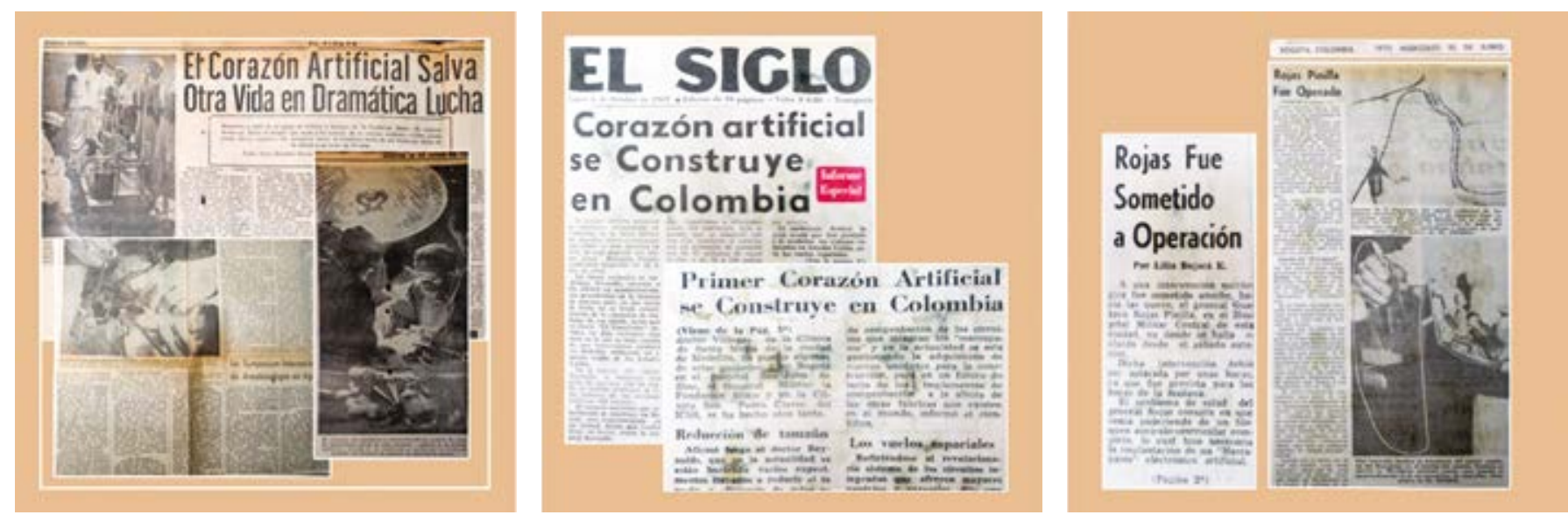

Imagen 6. Recortes de prensa digitalizada, colección personal Dr. Jorge Reynolds Pombo.

base en la categorización según el tipo de documento. (Silberschatz, 2006), la base de datos está categorizada por la siguiente categorización:

\section{Documento}

Sistema $=$ Análogo/Digital

Colección = Dr. Jorge Reynolds Pombo/electrofisiología del corazón/Sabio Caldas - mariposas Bicentenarias Representación del mensaje = Libro/revista/periódico/ folleto/informe....

$\mathrm{URL}=$

Título $=$

Palabras Claves $=$

Mes/año/día =

Medio=

Nombre del medio $=$

País/ciudad/autor/fotógrafo=
Colección patrimonio escrito=

Página álbum/fotógrafo=

Imagen $=$

Con esta herramienta, llamada Base documental Dr. Jorge Reynolds Pombo, se está recopilando todo el patrimonio escrito, grabado y de objetos, de igual manera sirve de repositorio de consulta, filtro de información según las categorías y generador de informes. Al momento de la investigación se han ingresado al sistema 150 documentos, se tiene un estimado de 1.000 documentos, proceso que se va generando.

Es importante resaltar la importancia patrimonial de estas fuentes y lo significativo de la información; los documentos análogos como los recortes de revistas y periódicos, datan desde 1958; y están entre ellos: noticias y reseñas de notas, artículos periodísticos, informes, entrevistas, eventos médicos, científicos, 
académicos y culturales del Dr. Jorge Reynolds Pombo, algunos ejemplos son:

Artículo en el periódico El Tiempo, con fecha de publicación junio de 1958, título, “El corazón artificial salva otra vida en dramática lucha" donde narra la vida de un joven con graves afecciones del corazón; realiza una descripción médica del caso y hace referencia a la tecnología e la época. De igual manera, en el periódico El Siglo, fue noticia, "Primer corazón artificial se construye en Colombia", y la cirugía del presidente Colombiano Rojas Pinilla, con implante de marcapasos, en 1970. Y así, más documentos, como las investigaciones con ballenas, el legado de las mariposas, los viajes al Everest, (Imagen 5). Todos los documentos harán parte de del catálogo que está en construcción, (Imagen 6).

Uno de los objetivos, fue definir las temáticas principales en torno a los procesos científicos y legado cultural del Dr. Reynolds, estas se definieron por agrupamiento de tipo de patrimonio, tanto científico como cultural. $Y$ es así que se precisaron 4 colecciones, estas son: a) Vida Dr. Jorge Reynolds Pombo, b) Vuelo de Morphos; cajas bicentenarias de insectos de Colombia, recopiladas por el Sabio Caldas en sus jornadas como expedicionario y heredadas por el Dr. Jorge Reynolds Pombo. c) Electrofisiología del corazón; estudios del corazón, ballenas, y desarrollo del marcapasos. D) Los tres Pombo; Legado del escritor colombiano de Rafael Pombo.

Dentro de los procesos de investigación formativa en la Fundación Universitaria del Área Andina, y, específicamente, con estudiantes del semillero de investigación del programa de Diseño Gráfico, se inicia la creación de productos gráficos y audiovisuales inspirados en estas colecciones. Podemos definir que, el proyecto originó procesos de investigación-creación y la generación de productos; vale referenciar el concepto contenido en el documento de medición de grupos de Colciencias, en donde se definen productos en esta categoría, como:

Obras, diseños y procesos de nuevo conocimiento, provenientes de la creación en artes, arquitectura y diseño, aquellas obras, diseños o productos resultantes de los procesos de creación que implican aportes nuevos originales e inéditos al arte, a la arquitectura, al diseño, a la cultura y al conocimiento en general a través de lenguajes simbólicos que expresan, interpretan y enriquecen de manera sustancial la vida intelectual, emocional, cultural y social de las comunidades humanas. (Colciencias, 2014).
Estos productos son obras de creación efímera, obras de creación permanente y obras de creación procesual. Con la estrategia de semilleros, el proyecto de investigación del museo y con necesidades gráficas, era pertinente generar una identidad visual y comunicativa, para estas colecciones. Como bien lo define Burcaw (1997), colecciones son el grupo de bienes culturales y singulares que tienen una intencionalidad y que hacen parte de una temática específica, es así que se diseñaron obras de creación permanente, iniciando con 3 identidades corporativas para las colecciones de Vuelo de Morphos, Los tres Pombo y Electrofisiología del Corazón. (Imagen 7).

Dentro de la misma estrategia de los semilleros, se realizaron ilustraciones inspiradas en el legado cultural del escritor Rafael Pombo, como desarrollo de productos de creación permanente. Poemas como El preludio de primavera, De noche y La hora de las tinieblas, inspiradores, como se visualiza en la Imagen 8.

De igual manera, se realizó un producto audiovisual animado, como intros (Introducción animada a un tema en una web) para la sala de Vuelo de Morphos, por parte de los investigadores en productos de creación permanente, se inicia una producción de obras para exposición itinerante de la historia del patrimonio científico y cultural del Dr. Jorge Reynolds Pombo con base en las fuentes fotográficas de los recortes de prensa y revista.

\section{Conclusiones}

En esta primera fase del macroproyecto, se logró la identificación de las fuentes de información, del patrimonio científico y cultural del Dr. Reynolds Pombo, el diseño de la estrategia para (I) Inventariar el conjunto de documentos de este patrimonio; (S) Sistematizar organizando y registrando el material encontrado por temática, colecciones y línea de tiempo de los documentos y (D) Digitalizar los documentos análogos para su exploración, captura y catalogación. El proceso investigativo se realizó y los instrumentos de recolección se crearon, se inició el proceso de digitalización. Este proceso es un trabajo de ejecución extenso para el que se recomienda seguir ejecutando la estrategia y realizar las obras de las colecciones itinerantes, buscando recursos humanos y tecnológicos para el desarrollo de esta estrategia.

El proyecto ha sido fuente de inspiración para la gestación de una cultura investigativa, el desarrollo disciplinar y la producción artística, en los estudiantes y docentes de los programas de pregrado de la Facultad de Diseño, 

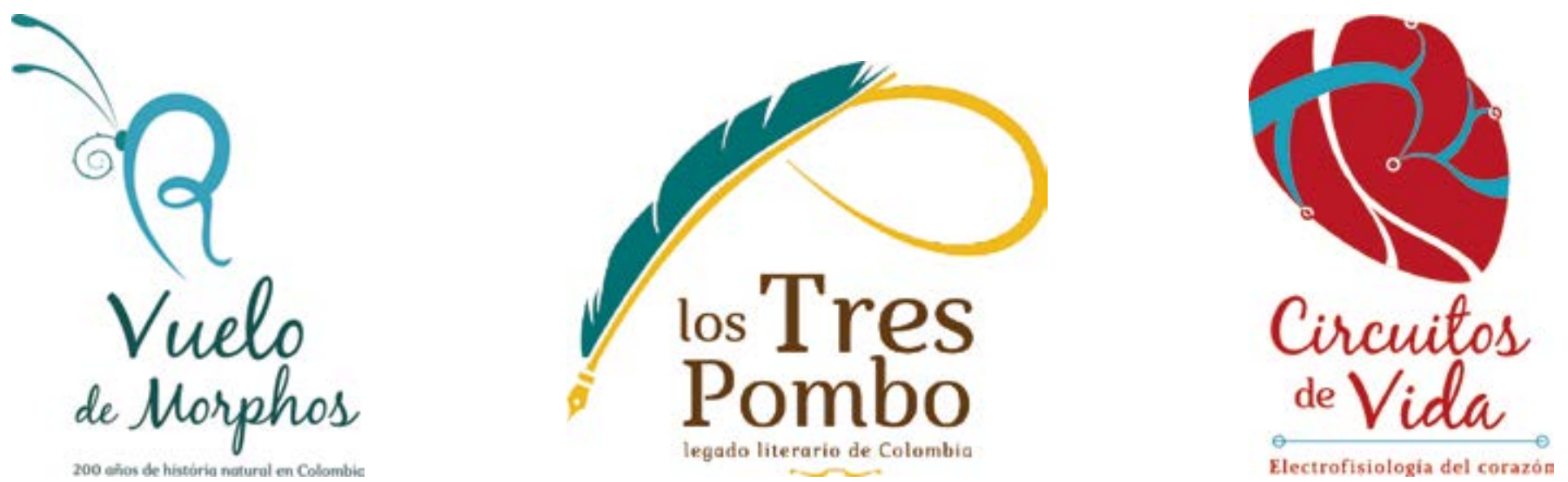

Imagen 7. Identidades corporativas de 3 colecciones del Museo Virtual. Autora: Tatiana Cancelado, Estudiante Semillero Punto D, Fundación Universitaria del Área Andina. (2015).

Comunicación y Bellas Artes, como, Diseño gráfico, de modas, animación y posproducción audiovisual, y también de la Facultad de Ciencias de la Salud, en el programa de Enfermería. El involucrar las temáticas del macroproyecto en los PPA, (Proyectos Pedagógicos de Aula), en los PISE (Proyectos Integradores de Semestre) y las opciones de grado en investigación, y creación de empresa, son proceso enriquecedores y significativos dentro de la formación de los estudiantes.

A través de la realización del proyecto, se evidencia la necesidad de involucrar tecnologías de la información y comunicación en las fases, el uso de software open source, así como de software propietario, en bases de datos, catalogación, digitalización, diseño, publicación. De igual manera, la adquisición de hardware y tecnologías táctiles, de obras itinerantes, como camino formador y complementario del Museo Virtual.

\section{Referencias}

Burcaw, G. E. (1997). Introduction to Museum Work, Walnut Creek. (3a ed.). Londres: Altamira Press.

Colombia, M. d. (2009). Curaduría en un museo. Bogotá:

Davallon, J. (1995). "Musée et muséologie.Introduction", in Musées et Recherche, Actes du colloquetenu à Paris, (les 29, 30 novembre et 1er décembre 1993), Dijon: OCIM.
Fajardo, C. R. (2017). Servicio Nacional de Geología y Minería. Recuperado de Museo_Geologico: http://www. sernageomin.cl/Museo_Geologico/documentos/Cramos. pdf

Galán, M. (2011). Metodología de la investigación: la investigación documental. Consultado, agosto 19 de 2015. En http://manuelgalan.blogspot.com/2011/09/ la-investgacion-documental_1557.html

García Cuetos, M. P. (2012). El patrimonio cultural: conceptos básicos. Prensa Universitaria de Zaragoza.

Garrido, M. R. (1996). Teoría e historia de la catalogación de documentos 23. pdf. Recuperado de http://infocuib.laborales.unam.mx/ ec08s02b/ archivos/data/1/23.pdf

Gómez, J., Grau, A., Giulia, A., Jabbaz, M. (n.d.). Tema_6_ Investigacion_documental - Técnicas Cualitativas de Investigación Social, tema_6_investigacion_ documental.pdf. Consultado agosto 19 de 2015. En http://ocw.uv.es/ciencias-sociales-y-juridicas/ tecnicas-cualitativas-de-investigacion-social/tema_6_ investigacion_documental.pdf

ICOM International Council of Museums. (2009).

Disponible en http://www.icom.org.

López, C. G. (2013). Guiones curatoriales, la idea. Revista INAH, 6. 
Morales, A. (2008). “Microsoft Word - fundamentos de la investigaci $323 \mathrm{~N}$ documental y la monograf $\backslash 315 a \backslash 205 "$ - fundamentos_investigacion. pdf. Recuperado de http://www.saber.ula.ve/ bitstream/123456789/16490/1/fundamentos_ investigacion.pdf

Museos, C. I. de. (2015). Definición del Museo- ICOM.

Quintanilla, O. (2005). catalog_prin_inc.PDF - cata_prin_ inc.pdf. Recuperado de http://sisbib.unmsm.edu.pe/m_ recursos/publicacion/presenta/pdf/cata_prin_inc.pdf

Rosell, A. R. (2000). Conservar (y actualizar) el patrimonio científico. Documento de trabajo.

Salazar, C.B. (2012). Conceptos generales de Museología. (1 ed.). Bogotá: Ministerio de Cultura.

Santibáñez, J. (2005). Los museos virtuales como recurso de enseñanza-aprendizaje. Recuperado de http://rabida.uhu.es/dspace/bitstream/ handle/10272/1310/b15280627.pdf?sequence=1
Solanilla, L. (2002). ¿Qué queremos decir cuando hablamos de interactividad? El caso de los webs de los museos de historia y arqueología. UOC Digit. HVM. Revista digital D'humanitats. DOI: https://doi. org/10.7238/d.v0i4.574

Torres Pombert, A. (2006). ¿Catalogación en el entorno digital?: una breve aproximación a los metadatos. ACIMED. 14(5). Recuperado de http:// scielo.sld.cu/scielo.php?script=sci_arttext\&pid=S102494352006000500009\&lng=es\&nrm=iso\&tlng $=$ es

UNESCO. (2005). Las tecnologías de la información.

Virtual, U., \& Virtual, M. (2011). "UCOMuseo Virtual", Museo y MetaMuseo Virtual. España: Universidad de Córdoba.
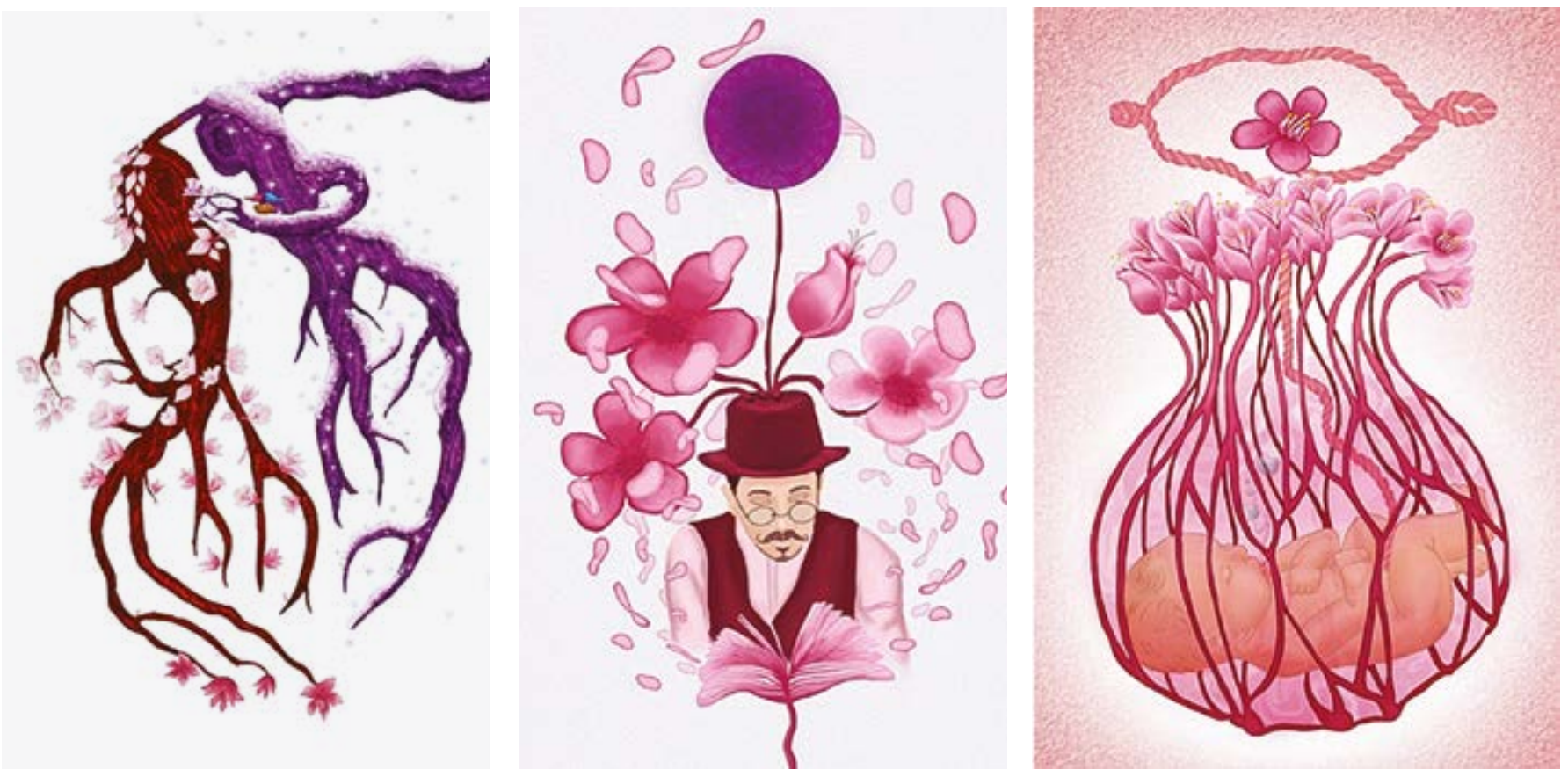

Imagen 8. Ilustraciones inspiradas en cuentos de Rafael Pombo. Autora: Mileydi Rodríguez, Estudiante Semillero Punto D, Fundación Universitaria del Área Andina. (2015). 